\title{
Ability of aphasic individuals to perform numerical processing and calculation tasks
}

\author{
Afásicos apresentam dificuldades para executar tarefas que envolvem processamento \\ numérico e de cálculo
}

Gabriela De Luccia ${ }^{1}$, Karin Zazo Ortiz²

\begin{abstract}
Objective: To compare performance on EC301 battery calculation task between aphasic subjects and normal controls of the same sex, age, and education. Method: Thirty-two aphasic patients who had suffered a single left hemisphere stroke were evaluated. Forty-four healthy volunteers were also selected. All subjects underwent a comprehensive arithmetic battery to assess their numerical and calculation skills. Performances on numerical processing and calculation tasks were then analyzed. Results: Aphasic individuals showed changes in their ability to perform numerical processing and calculation tasks that were not observed in the healthy population. Conclusion: Compared with healthy subjects of the same age and education level, individuals with aphasia had difficulty performing various tasks that involved numerical processing and calculation.
\end{abstract}

Keywords: aphasia, dyscalculia, stroke.

\section{RESUMO}

Objetivo: Comparar o desempenho em tarefas de cálculo através da bateria EC301 entre sujeitos afásicos e indivíduos normais pareando as variáveis sexo, idade e educação. Método: Foram avaliados 32 pacientes afásicos que sofreram lesão em hemisfério esquerdo único, concomitantemente com quarenta e quatro voluntários saudáveis. Todos foram submetidos a uma bateria de aritmética abrangente para avaliar habilidades numérica e de cálculo. Resultados: Os indivíduos afásicos apresentaram alterações no processamento numérico e tarefas de cálculo que não foram observadas na população saudável. Conclusão: Pacientes afásicos apresentam dificuldades para executar tarefas que envolvem processamento numérico e de cálculo em comparação com indivíduos saudáveis da mesma idade e escolaridade.

Palavras-chave: afasia, discalculia, acidente vascular encefálico.

Calculation ability represents an extremely complex cognitive process, which requires multifactorial processes, including verbal, spatial, memory, and executive functions ${ }^{1,2}$. The literature suggests that mathematical calculation performance can be damaged in cases of dementia, dysfunction, and/or brain injury ${ }^{3,4}$ and that such patients have difficulties with verbal, spatial, memory, and executive function abilities ${ }^{5-10}$.

Aphasic patients are more likely to exhibit mathematical difficulties, particularly in tests involving numerical transcoding, Arabic spelling, and oral Arabic ${ }^{3,5,11}$. The pattern of errors for a large sample of aphasic patients was analyzed, and the most severe impairment in calculation ability was found in global aphasics. Patients with Broca's and
Wernicke's aphasias performed similarly in quantitative terms, while patients with anomic aphasia exhibited fewer difficulties in making calculations ${ }^{12}$. Many observed numerical processing problems may also arise from other, nonlinguistic impairments frequently found in left hemispheric patients, including attentional deficits, short-term memory problems, or difficulties in monitoring complex sequences.

Considering the numerical and calculation skills acquired throughout life, Leonhard ${ }^{13}$ hypothesized the existence of three cognitive styles that adults use to perform calculations. Such a hypothesis suggests the existence of three groups of individuals, each predominantly using one of these styles. The first group would contain people who automatically calculate aloud, using the linguistic representations of numbers,

${ }^{1}$ Professor at Universidade Várzea Grande, Cuiabá MT, Brazil;

${ }^{2}$ Professor at Universidade Federal de São Paulo, Sao Paulo SP, Brazil.

Correspondence: Karin Zazo Ortiz; Departamento de Fonoaudiologia; Universidade Federal de São Paulo; Rua Botucatu 802; 04023-062 São Paulo SP - Brasil. E-mail: karinortizfono@epm.br

Contract/grant sponsor: Fundação de Amparo à Pesquisa do Estado de São Paulo (FAPESP)

Conflict of interest: There is no conflict of interest to declare.

Received 25 April 2013; Received in final form 12 August 2013; Accepted 04 September 2013. 
as waiters do when working out a bill. The second group would contain individuals who perform calculations in silence, as if there were a "mental page" on which the numbers are recorded and then calculated. The third group comprises individuals who calculate using visual diagrams that constitute their system of representing numbers, such as engineers and architects.

Whereas numerical processing and calculation can be performed in three different ways, there may be higher correlations between language and calculation for cultures in which mathematics is primarily based on verbal learning. As the technique for learning mathematics in Brazil is based on an oral code, language could be involved in processing the mathematical code for the Brazilian population; aphasic individuals would thus hypothetically be more susceptible to changes in number processing and calculation.

This study aimed to compare the performance of aphasic individuals and healthy controls on a comprehensive arithmetic battery.

\section{METHOD}

The data analyzed in the current study were collected in accordance with the Research Ethics Committee of UNIFESP, protocol no. 0346/04. All patients signed informed consent forms prior to participation.

To analyze the specific difficulties encountered in numerical processing and calculation tasks among the aphasic group, we compared the performances of aphasic adults and healthy controls on specific calculation tasks.

For the control group, 44 volunteers were selected $(74 \%$ female). The average education duration was $8.5 \pm 4.1$ years, and the average age was $40.6 \pm 16.0$ years. For the aphasic group, 32 patients ( $37 \%$ female) who had suffered a single left hemisphere stroke were evaluated. The mean age of the patients was $51.4 \pm 13.7$ years, and the mean education duration was $8.0 \pm 5.2$ years (Table 1 ).

Table 1. Group characteristics

\begin{tabular}{|c|c|c|c|c|c|}
\hline & \multicolumn{2}{|c|}{ Control group } & \multicolumn{2}{|c|}{ Aphasic group } & \multirow{2}{*}{$p$-value } \\
\hline & $\mathrm{n}$ & Mean (SD) & $\mathrm{n}$ & Mean (SD) & \\
\hline Age & 44 & 40.6(16.0) & 32 & $51.4(13.7)$ & $0.003 *$ \\
\hline Gender & & & & & $0.003 *$ \\
\hline Male & 15 & 26 & 22 & & \\
\hline Female & 29 & 74 & 10 & & \\
\hline Years of study & & & & & 0.662 \\
\hline $1-5$ years & 14 & 32 & 16 & 50 & \\
\hline $6-8$ years & 12 & 27 & 3 & 9 & \\
\hline $9-12$ years & 11 & 25 & 3 & 9 & \\
\hline$>12$ years & 7 & 16 & 10 & 32 & \\
\hline
\end{tabular}

*SD: standard deviation.
The general inclusion criteria were: no history of alcoholism or drug use; no use of psychotropic medications, except for atypical neuroleptics; and the absence of visual or auditory impairments that might affect test outcome. The control group consisted of individuals who were accompanying patients, family members, or friends.

This study included patients who had suffered a single left hemisphere stroke. Illiterate patients were excluded from the study, as were patients who presented with motor difficulties that prevented them from performing the tasks. All patients selected for the study were right-handed and were assessed at the Acquired Neurologic Disturbances of Speech and Language outpatient unit. All subjects were evaluated by a neurologist and underwent brain magnetic resonance imaging. Among the aphasic patients, 10 (32\%) had a lesion in the left parietal region, 9 (28\%) in the frontal-temporal-parietal, $3(9.4 \%)$ in the left temporal, 6 $(18.5 \%)$ in the left frontal-temporal, $3(9.4 \%)$ in the left temporal-parietal-occipital, and $1(3.15 \%)$ in the left parietaloccipital region. Furthermore, 16 (50\%) had anomic aphasia, $3(9.4 \%)$ had conduction aphasia, 4 (12.5\%) had Broca's aphasia, 1 (3.15\%) had transcortical sensory aphasia, 5 (16\%) had mist aphasia, and 3 (9.4\%) had global aphasia.

All patients underwent an evaluation of their calculation skills using the EC301 calculation battery. This battery is reputed to be the most frequently used method of assessing calculation abilities in adults ${ }^{14-16}$ and contains 13 different tasks ( 31 subtasks; Table 2): (1) counting; (2) dot counting; (3) transcoding; (4) arithmetic signs; (5) number comparison; (6) mental computation; (7) estimating the result of an operation; (8) number positioning on an analog scale; (9) writing down an operation; (10) written calculation; (11) perceptive estimation of quantity where subjects must estimate the weight, length, or number of objects shown in a picture; (12) contextual magnitude judgments; and (13) numerical knowledge.

Considering the numbers stimuli it was not necessary to translate the battery.

\section{Statistical Analysis}

The chi-squared $\left(\mathrm{X}^{2}\right)$ test (without the Yates' correction) was used to compare categorical data. Differences between the means of continuous data were tested using parametric and nonparametric tests. These tests, without exception, showed similar results; thus we have reported only the parametric test results. We used the Student's t-test ( $t$ ) for independent samples and the Mann-Whitney $U$ test for representative nonparametric samples. Women were chosen as a reference group for the categorical variable.

A p-value $<0.05$ was considered to indicate statistical significance. All analyses were calculated using the statistical package SPSS (Statistical Package for the Social Sciences). 
Table 2 Comparison of EC301 battery subtest scores between normal and aphasic subjects.

\begin{tabular}{|c|c|c|c|c|}
\hline Subtest & $\begin{array}{c}\text { Difference between } \\
\text { average }\end{array}$ & $95 \% \mathrm{Cl}$ & $t(74)$ & $P$ \\
\hline C1 & 30.6 & $17.9-43.3$ & 4.8 & $<0.001 *$ \\
\hline C2 & 24.7 & $11.4-38.1$ & 3.7 & $<0.001 *$ \\
\hline C3 & 41.3 & $24.3-58.4$ & 4.8 & $<0.001 *$ \\
\hline C4 & 12.6 & $3.7-21.6$ & 2.8 & 0.006 \\
\hline C5 & 11.6 & $2.6-20.6$ & 2.6 & 0.013 \\
\hline C6 & 12.3 & $0.5-24.1$ & 2.1 & 0.042 \\
\hline C7 & 15.7 & $4.6-26.7$ & 2.8 & 0.006 \\
\hline C8 & 17.1 & $4.3-29.9$ & 2.7 & 0.009 \\
\hline C9 & 44.6 & $32.0-57.2$ & 7.1 & $<0.001 *$ \\
\hline C10 & 46.3 & $30.4-62.1$ & 5.8 & $<0.001 *$ \\
\hline C11 & 36.6 & $23.4-49.9$ & 5.5 & $<0.001 *$ \\
\hline C12 & 54.0 & $39.7-68.3$ & 7.5 & $<0.001 *$ \\
\hline C13 & 37.2 & $23.2-51.2$ & 5.3 & $<0.001 *$ \\
\hline C14 & 46.5 & $32.7-60.3$ & 6.7 & $<0.001 *$ \\
\hline C15 & 42.1 & $27.4-56.9$ & 5.7 & $<0.001 *$ \\
\hline C16 & 41.9 & $28.9-55.0$ & 6.4 & $<0.001 *$ \\
\hline C17 & 42.8 & $27.4-58.1$ & 5.6 & $<0.001 *$ \\
\hline C18 & 14.5 & $4.2-24.7$ & 2.8 & 0.006 \\
\hline C19 & 29.8 & $17.5-42.1$ & 4.8 & $<0.001 *$ \\
\hline $\mathrm{C} 2 \mathrm{O}$ & 44.2 & $31.8-56.6$ & 7.1 & $<0.001 *$ \\
\hline C21 & 28.2 & $14.7-41.8$ & 4.2 & $<0.001 *$ \\
\hline $\mathrm{C} 22$ & 31.7 & $16.7-46.8$ & 4.2 & $<0.001 *$ \\
\hline $\mathrm{C} 23$ & 15.5 & $1.5-29.4$ & 2.2 & 0.030 \\
\hline $\mathrm{C} 24$ & 15.5 & $-0.3-31.2$ & 2.0 & 0.054 \\
\hline C25 & 26.6 & $6.8-46.5$ & 2.7 & 0.009 \\
\hline C26 & 39.6 & $23.3-55.9$ & 4.8 & $<0.001 *$ \\
\hline $\mathrm{C} 27$ & 38.1 & $20.7-55.4$ & 4.4 & $<0.001 *$ \\
\hline C28 & 40.1 & $24.1-56.1$ & 5.0 & $<0.001 *$ \\
\hline C29 & 25.3 & $12.6-38.1$ & 4.0 & $<0.001 *$ \\
\hline C30 & 26.4 & $15.4-37.4$ & 4.9 & $<0.001 *$ \\
\hline C31 & 13.8 & $3.9-23.7$ & 2.8 & 0.007 \\
\hline
\end{tabular}

1. Counting ( $\mathrm{C} 1, \mathrm{C} 2, \mathrm{C} 3)$; 2. Dot counting ( $\mathrm{C} 4, \mathrm{C} 5, \mathrm{C} 6, \mathrm{C} 7, \mathrm{C} 8)$ ) 3. Transcoding (C9, C10, C11, C12, C13, C14, C15); 4. Arithmetic signs (C16, C17); 5. Number comparison (C18, C19); 6. Mental computation (C20, C21); 7. Estimating the result of an operation (C22); 8. Number positioning on an analog scale (C23, C24); 9. Writing down an operation (C25); 10. Written calculation (C26, C27, C28); 11. Perceptive estimation of quantity (C29); 12. Contextual magnitude judgment (C30); 13. Numerical knowledge (C31).

\section{RESULTS}

There were no statistically significant differences between the control and aphasic groups when comparing their years of schooling (see Table 1) (8.5 \pm 4.1 vs. $8.0 \pm 5.2$ years; $95 \% \mathrm{CI}=-1.7$ to $2.6 ; \mathrm{t}(74)=0.439 ; \mathrm{p}=0.662$ ). However, those in the control group were significantly younger than those in the aphasic group (40.6 6.0 vs. $51.4 \pm 3.7$ years; 95\% $\mathrm{CI}=-17.7$ to $-3.7 ; \mathrm{t}(74)=-3.06 ; \mathrm{p}=0.003)$ and had a higher proportion of women $\left(74 \%\right.$ vs. $\left.26 \% ; \mathrm{X}^{2}=8.90 ; \mathrm{p}=0.003\right)$. Table 2 and Figure 1 show that the performance of patients with aphasia was significantly worse than that of the control group on subtests $\mathrm{C} 1, \mathrm{C} 2, \mathrm{C} 3, \mathrm{C} 9, \mathrm{C} 10, \mathrm{C} 11, \mathrm{C} 12, \mathrm{C} 13, \mathrm{C} 14$, C15, C16, C17, C19, C20, C21, C22, C26, C27, C28, C29, and C30 from the EC301 battery test.

\section{DISCUSSION}

The most important finding of this study is that aphasic individuals performed differently than healthy controls on numerical processing and calculation tasks. The association between aphasia and acalculia was not obvious, considering that case reports have shown two areas of dissociation between calculation and language: intact language functions and impaired calculation ${ }^{17}$, and, contrastingly, good calculation abilities despite severe language problems ${ }^{18}$.

The use of the EC301 battery test on healthy subjects and those diagnosed with aphasia was intended to provide an assessment of numerical processing and calculation after a brain injury. The task performance of stroke patients demonstrated that lesions in the left hemisphere had a deleterious effect; consequently, all aphasic patients may suffer the same negative effect in most numerical processing and calculation tasks. Table 2 compares the performance of the two groups on various subtests. Although the groups differed in age, we do not consider that this difference affected the results because there were no elderly subjects in our sample, and there is no evidence of cognitive changes at these ages ${ }^{19}$.

Certain points should be considered when explaining the poorer performance of aphasic patients. We found that aphasic patients had difficulties performing subtest $\mathrm{Cl}$ (oral number counting). Counting serially (automatic range) in threes, in tens, and in reverse order (back to front) requires praxis skills and prior learning ${ }^{20}$.The fact that all tasks were altered suggests that the inferior performance of the aphasic patients resulted not only from speech apraxia, which is commonly found in aphasic patients ${ }^{21}$ who sometimes have difficulty controlling the programming of their buccolaryngo-pharyngeal speech movements, and this gives the impression that they struggle to produce the intended sequence of sounds. They also have difficulties with verbal counting and learned numerical concepts ${ }^{16,21}$.

Differences in subtests C16 (naming arithmetic signs aloud) and $\mathrm{C} 17$ (writing arithmetic signs under dictation) were also observed when comparing the control group with the aphasic patients. In this study, we predicted the occurrence of asymbolic acalculia ${ }^{22}$, where sign changes or naming failures were directly related to semantic changes and anomalies that are commonly found in aphasics.

Differences between the aphasic and control groups were also found in comparisons of magnitude, where the patient had to choose the larger of two numbers written orthographically (Table 2, Figure 1; subtest C19). This result may be related to difficulties in reading figures or understanding quantities expressed by numerals ${ }^{3,23}$. During the test, patients were often guided by the extension of written numbers rather than their magnitude. 


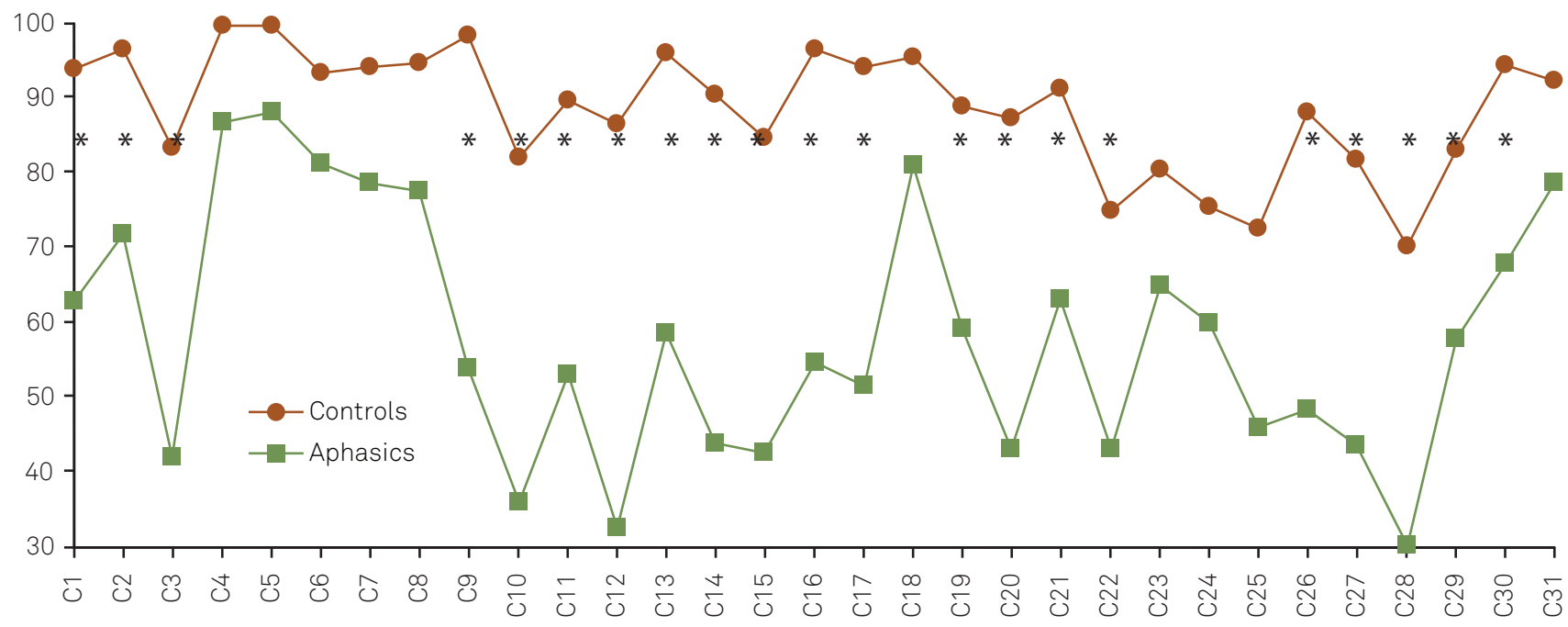

Figure 1. Mean percentage of correct responses in each EC301 battery subtest for the control and aphasic groups. 1. Counting (C1, C2, C3); 2. Dot counting (C4, C5, C6, C7, C8); 3. Transcoding (C9, C10, C11, C12, C13, C14, C15); 4. Arithmetic signs (C16, C17); 5. Number comparison (C18, C19); 6. Mental computation (C20, C21); 7. Estimating the result of an operation (C22); 8. Number positioning on an analog scale (C23, C24); 9. Writing down an operation (C25); 10. Written calculation (C26, C27, C28); 11. Perceptive estimation of quantity (C29); 12. Contextual magnitude judgment (C30); 13. Numerical knowledge (C31).

Subtests C20 (resolution of oral calculations) and C21 (resolution of graphical calculations) also revealed differences between the groups. The aphasic patients had lower scores on the simple mental operations of addition, subtraction, multiplication, and division, presented both orally and graphically (Figure 1; C20, C21). The aphasic patients performed better in simple addition tasks than on subtraction and multiplication. However, they performed significantly worse on multiplication tasks than on subtraction and division tasks. This result can be explained by the way multiplication rules are learned, e.g., in multiplication tables using verbal cues or rhymes, a training method commonly used in Brazil. This does not occur in operations that are less systematically studied, suggesting that multiplication rules are stored at a phonological level, thus producing greater impairment in patients with brain injuries ${ }^{24}$. However, visuospatial interference cannot be ruled out, especially in solving graphical computations comprised of more than one digit, in which arithmetic rules are directly involved.

In evaluating written calculations of greater complexity, we observed significant differences between the control and aphasic groups for subtests C26 (solving addition calculations), C27 (solving subtraction calculations), and C28 (solving multiplication calculations), i.e., in all operations (Table 2, Figure 1). Calculations of higher complexity using specific operational properties were more difficult for aphasic patients to perform; these included summation of decimals, recovering previously memorized numerical facts, counting on fingers, counting from the value of the first summand, and estimating ${ }^{22}$. Furthermore, as multiplication calculations may involve successive additions, and division calculations may involve successive subtractions, these necessary rules of decomposition and grouping could also explain the inferior performance of aphasics in these operations.

We also investigated the performances on addition, multiplication, and subtraction operations when arithmetic rules, such as regrouping, borrowing, and visuospatial organizing, were involved. Given the difficulties encountered in these tasks, we suggest that a failure to activate calculation procedures and arithmetic rules in aphasic patients is most likely to occur because these processes are related to regrouping rules (i.e., when the sum of an addition yields a value greater than 10 and that value must be regrouped and summed with the number to its left), borrowing rules (i.e., when the number to be subtracted from the numerator is smaller than the denominator), and visuospatial rules (i.e., for multiplication tests with more than two digits, in which the numbers must be grouped below the predecessor for the sum to be carried out properly). Changes in understanding and lexical and graphical difficulties, both commonly found in aphasics, may also affect performance on these tasks ${ }^{23}$. Furthermore, difficulties in working memory can also interfere with the regrouping and borrowing tasks ${ }^{24}$ involved in addition, multiplication, subtraction, and division calculations, as there may be changes in executive functions, principally attention. In such cases, memory often depends on the central executive, which is the center that regulates receiving and storing information. Conversely, both subtraction and division can be resolved using a visuospatial sketch $\mathrm{pad}^{25}$. They therefore do not require verbal components for their execution and are solved with less difficulty by aphasics, who typically have more difficulty in the phonological field. 
When comparing the two groups, significant differences were also observed in three further tests (Table 2, Figure 1; subtests 22, 29, 30). Subtest 22 asks the patient to make an estimate or approximation of the result of a written calculation without actually performing the operation. The purpose of this task is to investigate the performance of these subjects in activities that more closely resemble those of daily life. The same purpose applies to subtest C29, in which weight, height, and quantity estimates are required, and subtest C30, in which the task is to semantically interpret numbers in contextual situations. These tasks involve abstract calculations, numerical inferences, estimations of numerical magnitude, and previous numerical knowledge ${ }^{23}$. Magnitude judgment seems to use the same storage systems as visuospatial information and requires attentional resources that also seem to be involved in encoding this type of information; this appears to be compromised in the aphasic population ${ }^{24,25}$. Our results thus suggest that mathematical skill impairment in aphasic individuals goes beyond performing arithmetic calculations and that this group thus cannot adequately perform simple daily living activities.

As expected, all transcoding tests $(\mathrm{C} 9, \mathrm{C} 10, \mathrm{C} 11, \mathrm{C} 12, \mathrm{C} 13$, $\mathrm{C} 14$, and $\mathrm{C} 15)$ showed the greatest differences between the groups (Table 2).

Numerical transcoding ability depends on a central component that performs all transcoding and calculations ${ }^{26}$. For numerical comprehension or calculations, mechanisms are necessary to translate numerical inputs, whether in orthographic, numeric, or oral form. Moreover, numerical proction mechanisms have implications that require translation and abstract representations of the appropriate forms of output for each notation system (oral, orthographic, or numeric). To complete this process, a distinction must also be made between lexical and syntactic numerical processing, in which a series of oral, orthographic, and numeric transformations are performed in numeric comprehension.

During the transcoding tests in this study, lexical and syntactical errors were observed in most cases, and misspellings and omissions were noted in all types of aphasia. A relationship was observed between language and mathematics for all tasks involving language and arithmetic skills, such as transcoding tests.

Attention should also be paid to developmental factors and syntactic and phonological error patterns in the Portuguese language to verify whether the process of transcoding between different number representations has language-specific idiosyncrasies ${ }^{27}$.
Transcoding requires a numerical understanding of mechanisms within an abstract internal representation, which is translated as producing mechanisms that are written in Arabic numerals, spoken, or written in words, mainly in the Portuguese language. Considering the many skills involved in this process, patients with brain injuries are very likely to encounter major difficulties, as numerical transcoding ability is central to the discussion of the relationship between language and mathematics and seems to be a skill that combines both mathematical and linguistic components. Based on this assumption, emissive changes-including paraphasias, anomic behavior, reduction, agrammatism, and perseverations that may be present in most aphasics-could interfere with calculation skills. With the exception of the distinction between syntactic and lexical mechanisms of aphasic subjects, McCloskey's model $^{26}$ can easily account for the transcoding deficit because access to the Arabic component is mediated using unique semantics, independent of the input code. This theoretical framework also assumes a three-phase processing mechanism: the first phase involves transcoding Arabic numerals to their verbal forms, the second phase transcodes from verbal to orthographic, and the third phase transcodes from orthographic to Arabic. These steps also involve developing a semantic representation of input mechanisms. We might first suppose that a deficit related to inbound access to the verbal orthographic component could lead to problems in reading aloud and verbal comprehension tasks. A deficit related to access to the Arabic production component would then lead to a similar performance level, regardless of the verbal input code. In this study, we observed that aphasics had greater difficulty in orthographic transcoding, i.e., they recognized the Arabic numeral in most cases, but when they were required to convert such a numeral to an orthographic form, they failed. This finding confirms McCloskey's model ${ }^{26}$, in which the response is independent of the input code and the syntactic and lexical potential of the subject being assessed.

The present study should be interpreted in the light of some limitations: the question of whether numerical and language systems are dependent or independent remains unclear and must be investigated in further studies.

In conclusion, individuals with aphasia have more difficulty in carrying out tasks involving number processing and calculation than healthy subjects of the same age and education level.

\section{References}

1. Ardila A, Galeano, L.M, Rosselli M. Toward a model of neuropsychological activity. Neuropsychol Rev 1998;8:171-190.
Nieder A, Dehaene S. Representation of numbers in the brain. Ann Rev Neurosc 2009;32:185-208. 
Grafman J, Kampen D, Rosenberg J, Salazar AM, Boller F. The progressive breakdown of number processing and calculation ability: a case study. Cortex 1989;25:121-133.

4. Mantovan MC, Delazer M, Ermani M, Denes, G. The breakdown of calculation procedures in Alzheimer's disease. Cortex 1999;35:21-38.

5. Basso A, Burgio F, Caporali A. Acalculia, aphasia and spatial disorders in left and right brain- damaged patients. Cortex 2000;36:265-280.

6. Basso A, Caporali A, Faglioni P. Spontaneous recovery from acalculia. J Internat Neuropsychol Soc 2005;11:99-107.

7. Deloche G, Seron X. A differential analysis of skills in transcoding quantities between patients with Broca's and Wernicke's aphasia. Brain 1992;105:719-733.

8. Hècaen H, Angelergues R, Houiller, S. Les Variétés acalculias au cours des Cliniques des lesions rétrorolandiques: Apprche statistique du problème. Rev Neurol 1961;105: 85-103.

9. Jensen, MB. The accountant who lost arithmetic: a case report of acalculia with a left thalamic lesion. J Med Cases 2010;1:92-93.

10. Rosselli M, Ardila A. Calculation deficits in patients with right and left hemisphere damage. Neuropsychologia 1989;27:607-617.

11. Dellatolas G, Deloche G, Salinas D. Assessment of calculation and number processing using the EC-301 battery: cross-cultural normative data and application to left-and-right brain damage patients. $J$ Internat Neuropsychol Soc 2001;7:840-859.

12. Delazer M, Girelli L, Semenza C, Denes G. Numerical skills and aphasia. J Internat Neuropsychol Soc 1999;5:213-221.

13. Leonhard,K. Ideokinetic aphasia and related disorders. In: Deloche G, Lessa L, Rodrigues M, Rodrigues N (Eds.). Themes in neurolinguistics, acalculia and aphasia. São Paulo: Tec Art 1993:103-106.

14. Deloche G, Seron X, Larroque C, et al. Calculation and number processing: assessment battery; role of demographic factors. J Clin Exp Neuropsychol 1994;16:195-208.
15. De Luccia G, Ortiz KZ. Performance of a Brazilian population in the EC 301 calculation and number processing battery: a pilot study. Arq Neuropsiquiatr 2009;67:432-438.

16. Delazer L, Girelli A, Granà F. Domahs number processing and calculation - normative data from healthy adults. Clin Neuropsychol 2003;17:331-350.

17. Warrington EK. The fractionation of arithmetical skills: a single case study. Quart J Exp Psychol 1982;34:31-51.

18. Rossor MN, Warrington EK, Cipolotti L. The isolation of calculation skills. J Neurol 1995;242:78-81.

19. Soares E, Ortiz K. Influence of schooling on language abilities of adults without linguistic disorders. São Paulo Med J 2009;127:134-139.

20. Geary DC. Reflections of evolution and culture in children's cognition. Implications for mathematical development and instruction. Am Psychol 1995;50:24-37.

21. Basso A, Cattaneo S, Girelli L, et al. Treatment efficacy of language and calculation disorders and speech apraxia: a review of the literature. Eur J Phys Rehab Med 2011;47:101-121.

22. Ferro JM, Botelho M. Alexia for arithmetical signs. A cause of disturbed calculation. Cortex 1980;16:175-180.

23. Baldo JV, Dronkers NF. Neural correlates of arithmetic and language comprehension: a common substrate? Neuropsychol 2007;45:229-235.

24. Miyake A, Carpenter PA, Just MA. A capacity approach to syntactic comprehension disorders: making normal adults perform like aphasic patients. Cognit Neuropsychol 1994;11:671-717.

25. Lee KM, Kang SY. Arithmetic operation and working memory: differential suppression in dual tasks. Cognition 2002;83:63-68.

26. McCloskey M. Cognitive mechanisms in numerical processing: evidence from acquired dyscalculia. Cognition 1992;44:107-157.

27. Freitas NL, Ferreira FO, Haase VG. Language and mathematics: a study about relations between cognitive abilities, linguistics and arithmetic. Ciências Cognição 2010;15:111-125. 